\title{
SHP-1 Agonist SC-43
}

National Cancer Institute

\section{Source}

National Cancer Institute. SHP-1 Agonist SC-43. NCI Thesaurus. Code C156695.

An orally available, small molecule agonist of Src homology region 2 domain-containing phosphatase-1 (SHP-1; tyrosine-protein phosphatase non-receptor type 6; PTPN6) with potential antineoplastic activity. Upon administration, SHP-1 agonist SC-43 enhances SHP-1 activity by impairing the association between the $\mathrm{N}$-terminal Src homology 2 ( $\mathrm{N}$ $\mathrm{SH} 2$ ) domain and the protein tyrosine phosphatase (PTP) domain of SHP-1, triggering a conformational change of SHP-1 and relieving its autoinhibition. Activation of SHP-1 represses signal transducer and activator of transcription 3 (STAT3) signaling by inhibiting constitutive and interleukin-6 (IL-6)-induced ST AT 3 phosphorylation. The STAT 3 pathway is overly active in many cancer types and is implicated in cancer stem cellmediated growth, recurrence, stemness, and resistance to conventional chemotherapies. 